\title{
Comunicación
}

\section{NIVELES SÉRICOS REFERENCIALESDEUREA, CREATININA Y ANÁLISIS FÍSICO-QUÍMICO DE LA ORINA EN Saimiri boliviensis}

\author{
Henry Arias Ch. ${ }^{1}$, Olga Lí E. ${ }^{2}$, Arnaldo Alvarado $S .{ }^{2}$ y Nofre Sánchez . $^{3}$
}

\begin{abstract}
The purpose of the study was to establish reference values for serum urea and creatinine, and for physical and chemical analysis in urine in Saimiri boliviensis. Fifteen females and 15 males raised in captivity at the Centro de Reproducción y Conservación de Primates No Humanos, Iquitos, Peru were used. Mean values of urea and creatinine were $66.7 \pm 25.2$ and $2.0 \pm 0.5$ respectively, and without statistical differences between sexes. Mean values for $\mathrm{pH}$ was $6.9 \pm 0.7$ and for specific gravity was $1.021 \pm 0.004$. Urea and creatinine values were higher to those reported for Aotus nancymae.
\end{abstract}

Key words: Saimiri boliviensis, uroanalysis, urea, creatinine

El mono Saimiri boliviensis es utilizado extensamente en diversos estudios experimentales de enfermedades que afectan al hombre tales como leishmaniasis y malaria, así como en el estudio de virus oncogénicos y no oncogénicos (Pritchard, 1989). La presentación de problemas renales tiene especial importancia en primates en cautiverio, siendo las patologías más comunes la pielonefritis, nefrocalcinosis y la glomerulonefritis (Bureck et al., 1988; Abee, 1989). Factores de estrés y cambios en la dieta han sido sugeridos como posibles causas de nefropatías. El presente trabajo se realizó para determinar los niveles séricos referenciales de urea, creatinina y análisis físico-químico de la orina en Saimiri boliviensis aparentemente sanos.

Se utilizaron 30 monos Saimiri boliviensis (15 machos y 15 hembras) nacidos en cautiverio con edades entre los 10 meses y 2 años de edad, y cuya alimentación estaba basada en plátano, agua ad libitum, y galletas preparadas en el Centro de Reproducción y Conservación de Primates No Humanos (CRCP) del Instituto Veterinario de Investigaciones Tropicales y de Altura, situado en la ciudad de Iquitos, Loreto.

Se colectó $2 \mathrm{ml}$ de sangre de la vena femoral, previa anestesia con clorhidrato de ketamina $(8 \mathrm{mg} / \mathrm{kg})$ para la determinación de los niveles séricos de urea y creatinina. Así mismo, se tomó una muestra de orina para su análisis físico-químico.

Los valores de urea y creatinina por sexo y para la población total se muestran en el Cuadro 1 . No se encontró diferencias estadísticas entre sexos.

\footnotetext{
I Práctica privada

${ }^{2}$ Laboratorio de Patología Clínica, FMV-UNMSM

${ }^{3}$ Centro de Reproducción y Conservación de Primates No Humanos, IVITA-Iquitos
} 
Cuadro 1. Niveles séricos de urea y creatinina, y análisis físico químico de orina (promedio \pm desviación estándar) de monos Saimiri boliviensis aparentemente normales

\begin{tabular}{lcccc}
\hline & $\begin{array}{c}\text { Urea } \\
(\mathrm{mg} / \mathrm{dl})\end{array}$ & $\begin{array}{c}\text { Creatinina } \\
(\mathrm{mg} / \mathrm{dl})\end{array}$ & $\mathrm{pH}$ & Gravedad específica \\
\hline Macho & $73.0 \pm 28.5$ & $2.0 \pm 0.6$ & $6.9 \pm 0.8$ & $1.022 \pm 0.004$ \\
Hembra & $60.5 \pm 19.6$ & $3.0 \pm 0.3$ & $6.9 \pm 0.7$ & $1.020 \pm 0.004$ \\
\hline Total & $66.7 \pm 25.2$ & $2.0 \pm 0.5$ & $6.9 \pm 0.7$ & $1.021 \pm 0.004$ \\
\hline
\end{tabular}

El análisis de la orina indicó un color amarillo ámbar, translúcido y de olor sui generis. El valor del $\mathrm{pH}$ y gravedad específica se muestra en el Cuadro 1.

En el análisis de la orina se encontró reacciones negativas a leucocitos, nitritos, proteína, bilirrubina, glucosa y sangre oculta.

Los resultados obtenidos para la urea y la creatinina concuerdan con los notificados por otros investigadores. No obstante, se encontró algunos animales con proteinuria, haciendo suponer que existen animales con problemas renales sin presentar manifestaciones clínicas. Se encontraron valores mayores tanto en la urea como en la creatinina en relación a los encontrados para la especie Aotus nancymae (Vásquez, 2000), el cual se realizó bajo un mismo régimen alimenticio, edad y medio ambiente.

\section{Lmpratura Citada}

1. Abee, C.R. 1989. The squirrel monkey in biomedical research. Institute of Laboratory Animal Resources News 31: 11-20.

2. Bureck, J.O.; P. Duprat; R. Owen; C.P. Peter; M.J. Van Zwieten. 1988. Spontaneous renal disease in laboratory animals. Internat. Rev. Exper. Pathology 30: 231-319.

5. Pritchard, J.L. 1989. Hepatitis research in a non-human primates: A bibliography, 1983-1988. Arch. Primate Information Center, Seatle 20: 51-60.

6. Vásquez, A. 2000. Niveles séricos referenciales de urea, creatinina y análisis físico-químico de la orina en primates (Aotus nancymae). Tesis Bachillerato. Fac. Med. Vet., Univ. Nac. Mayor San Marcos. 37 p. 